Yüzüncü Yil Üniversitesi
Tarim Bilimleri Dergisi

Araştırma Makalesi (Research Article)

\title{
Türkiye'de Ceviz Üretimi, Dış Ticareti ve Rekabet Gücü
}

\section{İsmail GÜVENÇ*1, Ahmet KAZANKAYA ${ }^{2}$}

${ }^{1}$ Kahramanmaraş Sütçü İmam Üniversitesi, Ziraat Fakültesi, Bahçe Bitkileri Bölümü, 46040, Kahramanmaraş, Türkiye

${ }^{2}$ Van Yüzüncü Y1l Üniversitesi, Ziraat Fakültesi, Bahçe Bitkileri Bölümü, 65080, Van, Türkiye

*Sorumlu yazar e-posta: ismailguvenc@ksu.edu.tr

\section{Makale Bilgileri}

Geliș: 29.05 .2019

Kabul: 05.08.2019

Online Yayınlanma 30.09.2019

DOI: $10.29133 /$ yyutbd.569905

Anahtar kelimeler

Ceviz,

İhracat,

Rekabet gücü,

Üretim.
Öz: Bu çalışmada Türkiye meyveciliğinde önemli bir yere sahip olan cevizin üretimi, dış ticareti ve rekabet gücü incelenmiştir. Türkiye'de 2017 verilerine göre 210 bin ton civarında ceviz üretilmiştir. Dünya ceviz üretiminin \% 5.20'i Türkiye'de üretilmektedir. Türkiye'nin cevizde yeterlilik durumu 2000'de \%93.9 iken 2017 'de \% 76.7'e düşmüştür. Son y1llarda Türkiye'nin toplam ceviz ihracatı ve ithalatı sırasıyla 8.1 ve 66.01 bin ton kadardır. Bu verilere göre Türkiye ceviz ihtiyacının bir kısmını ithalat yoluyla temin etmektedir. Türkiye ceviz dış ticaretinde açık veren bir ülke durumundadır. Bunların yanında Türkiye'nin cevizde rekabet gücü (karşılaştırmalı üstünlüğünün) 2012-2015 döneminde orta derecede iken 2016 yılında bir avantaja sahip olmadığı tespit edilmiştir. Bununla birlikte Türkiye'nin ceviz sektöründe alacağı önlemlerle üretim, yeterlilik, ihracatta rekabet gücünü artırması mümkündür.

\section{The Production, Foreign Trade and Competition Power of Walnuts in Turkey}

\section{Article Info}

Received: 29.05.2019

Accepted: 05.08.2019

Online Published 30.09.2019

DOI: $10.29133 /$ yyutbd.569905

Keywords

Walnuts with Shell,

Export,

Competition power,

Production.

\begin{abstract}
In this study, it was evaluated the production, foreign trade and competition power of walnuts with shell, which has a significant value in Turkey. According to 2017 data, it was produced more than 210 thousand tons of walnuts in Turkey. Turkey has $5.2 \%$ of production of walnuts with shell in the world. National self-sufficiency of walnut production in Turkey decreased from $93.9 \%$ in 2000 to $76.7 \%$ in 2017 . In recent years, total walnut exports and imports in Turkey are respectively 8.1 and 66.01 thousand tons. Thus Turkey is to provide a portion of the walnut needs through imports, and Turkey has a deficit of foreign trade in walnut. While Turkey's competitiveness (comparative advantages) in walnut was moderate during the period 2012-2015, it has been determined not to have an advantage in 2016. Besides, it is possible to increase production, qualification, and competitiveness in export by means of the measures taken in walnut sector.
\end{abstract}

\section{Giriş}

Cevizin anavatanı arasında Türkiye'nin de bulunduğu sert kabuklu bir meyve türüdür. Bu tür dünyada Anadolu veya İran cevizi olarak da bilinmektedir (Özçağıran ve ark., 2007). Ceviz latince tür ismi (Juglans regia L.) Juglans adlı bir kelimeden gelmekte olup, bu kelime Tanrını meyvesi anlamındadır. Romalılar da cevizi Tanrının meyvesi anlamındaki bu kelime ile isimlendirmişlerdir. Türkiye'de de ceviz yetiştiriciliği oldukça eski tarihlere dayanır. Nitekim Osmanlı Tahrir 
Defterleri'nin bazılarında (Yinanç ve Elibüyük, 1988) Anadolu'da on beşinci yüzyılda ceviz yetiştiriciliğinin var olduğuna dair bilgilere rastlanılmaktadır.

Ceviz besin olarak değerli bir kuru meyvedir. İç ceviz; \% 65-70 doymamış yağ asitleri ve\%1416 protein yanında vitamin ve mineraller bakımından da zengindir. Bu besin unsurları bakımında zengin olması insan beslenmesi ve sağlığı bakımından önemini artırmaktadır. Ceviz taze veya kuru olarak tüketilebileceği gibi şekerleme ve şıra ürünlerinin yapımında da hammadde olarak kullanılmaktadır. Bunların yanında gövde ve dallarında elde edilen kerestesi mobilya sanayinde oldukça değerlidir (Özçağıran ve ark., 2007; Şen, 2011; Yücer, 2013).

Bahçe ürünlerinin Türkiye'nin dış satımında karşılaştırmalı üstünlüklerini inceleyen veya güncel durumunu yansıtan araştırma sayısı oldukça azdır. Ülkemizin bazı meyve-sebzelerde 19932012 yıllarına ait verilerden yararlanarak ihracatta önem derecesi karşılaştırmalı üstünlükler varsayımı metodu ile belirlenmiştir (Erkan ve ark., 2015). Başka bir çalışmada da Türkiye'nin, ihraçta önemli olan bahçe bitkileri ürünlerinde (incir, kuru üzüm, fındık, fıstık ve kuru kayısı) karşılaştırmalı üstünlüğünün var olduğu tespit edilmiştir (Erkan, 2012a). Diğer yandan sebze ihracatında değişik ülkelerin durumunun incelendiği çalışmalarda mevcuttur: Macaristan'ın karşılaştırmalı üstünlüğünün var olduğu (Fertő ve Hubbard, 2001); Slovenya'nın ise karşılaştırmalı üstünlüğünün ise var olmadığ1 (Bojnec ve Fertö, 2006) belirlemiştir.

Cevizin üretim, ihracat ve rekabet gücünü inceleyen çalışmalar oldukça sinırlıdır. Bu nedenlerle bu incelemede Türkiye'de ceviz önemli bir kuru meyve olan cevizin üretimi, rekabet gücü ve dış ticareti değerlendirilmiştir.

\section{Materyal ve Yöntem}

$\mathrm{Bu}$ incelemede, Türkiye'nin ceviz üretimi, rekabet gücü ve dış ticaret durumunu tespit edilmesi amacıyla Birleşmiş Milletler Gıda ve Tarım Örgütü’nün (Anonim, 2018a) istatistikleri esas alınmıştır. Çalışmada FAO’nun ürün kodları (Item code) 222 olan kabuklu ceviz (Walnuts, with Shell) ait veriler kullanılmıştır. Ayrıca çalışmada TUİK (Anonim 2018b) ile Tarım ve Orman Bakanlığı, Bitkisel Üretim Genel Müdürlüğü'nün (Anonim, 2018c) sebze üretimi ile ilgili verilerinden de yararlanılmıştır.

Balassa'nın (Balassa Endeksi) Açıklanmış Karşılaştırmalı Üstünlük (AKÜ) Katsayısı olarak da adlandırılmaktadır. AKÜ bir bölge veya ülkenin belli ürünlerde (sektörlerde) karşıllaştırmalı üstünlüğe sahip olup olmadığını ortaya koymaktadır: Kısaca herhangi bir ürünün (malın) ülkenin toplam ihracatındaki payının, o ürünün dünyanın toplam ihracatındaki payını açılar. Daha açık olarak AKÜ; ülkenin bir ürünün ülke içi uzmanlaşması ile dünyanın veya bölgenin uzmanlaşma düzeylerini karşılaştırmaktadır (Beningo, 2006; Bashimov, 2016). Yani AKÜ endeksinin payında, ürünün ulusal ihracattaki oranı (\%); paydada ise, söz konusu ürünün dünyanın toplam ihracatındaki oranı vardır (Mykhnenko, 2005). AKÜ katsayısının belirlenmesinde önceki araştırıcıların hesaplama tekniklerinden yararlanılmıştır (Erkan ve ark., 2015; Bashimov, 2016)

Herhangi bir ürünün AKÜ katsayısının 1'den büyük olması, incelenen zaman aralığında bölgenin (Ülke) ihracat payının, o dönemde toplam dünya ihracatındaki payından büyük olduğu anlamına gelmektedir (Bashimov, 2016). Yani incelenen bölge veya ülkenin incelenen ürün bakımından uzmanlaşmış ve ihracatında rekabet gücüde bulunmaktadır (Coxhead, 2007).

Balansa endeksine göre bir ülke veya bölgenin incelenen ürünün ihracatında uzmanlaşmış olması ve dış ticaret performansının yüksek olması için AKÜ katsayısının sıfırdan büyük $\left(\ln A K \ddot{U}_{\mathrm{kt}}>\right.$ 0) olması gerekir (Yılmaz ve Ergun, 2003). Bununla birlikte AKÜ katsayısını 4 kademeli olarak değerlendirilmektedir (Hinloopen ve Marrewijk, 2001). Bunlar (1)- Rekabet gücü yoktur:0 $<$ AKÜ $\leq 1$; (2)- Zayıf bir rekabet gücü vardır: $1<\mathrm{AKÜ} \leq 2$; (3)-Orta derecede rekabet gücü vardır: $-2<\mathrm{AKÜ} \leq 4$; (4)- Güçlü bir rekabet gücü vardır: $4<$ AKÜ.

Bir ürünün yeterlilik seviyesi üretim, ihracat ve ithalat miktarları dikkate alınarak ortaya konulmaktadır. İthalat miktarı ile ihracat miktarı arasındaki fark ile üretim miktarının toplamı iç pazar gereksinimi (\%) olarak belirlenmektedir $($ Yeterli = Üretim / (İhracat-İthalat) + Üretim $)$. 


\section{Bulgular}

\section{1. Üretim ve yeterlilik}

Toplam ceviz üretimi hem Dünya'da hem de Türkiye'de artmaktadır. Nitekim Dünya ceviz üretimi 2005 'de 1,80 milyon ton iken 2 katından (\% 207,72) daha fazla artarak 2016 yılında ise 3,75 milyon tona yükseldiği belirlenmiştir (Çizelge 1). Dünyadaki ceviz üretimine paralel olarak aynı oranda olmasa da Türkiye ceviz üretimi de artmıştır: Türkiye'nin2005 y1lında 150 bin ton olan ceviz üretimi 2017 'de 210 bin tona artmıştır. Türkiye'nin ceviz üretiminde 2004-2017 döneminde 1,40 kat artmıştır. Türkiye'nin Dünya ceviz üretimindeki payı 2005 y1lında \%8,31 iken 2016 yılında \% 5,20'e gerilemiştir (Çizelge 1). Bu verilere göre Türkiye'nin ceviz üretimindeki artış dünyada üretimindeki artıştan daha azdır.Buna rağmen Türkiye önemli bir ceviz üreticisi ülke olup Dünya ceviz üretiminde 4. Sırada bulunmaktadır. Türkiye yanında önemli ceviz üreticisi ülkeler arasında Çin, ABD, İran, Meksika, Ukrayna, Şili, Özbekistan yer almaktadır. Ceviz üretiminde önemli paya sahip olan bu 8 ülke Dünya ceviz üretiminin \% 89,93'ü gerçekleştirmektedir (Çizelge 2).

Çizelge 1. Dünya ve Türkiye'de ceviz üretimi

\begin{tabular}{|c|c|c|c|c|c|}
\hline \multirow[b]{2}{*}{ Yil } & \multicolumn{2}{|c|}{ Dünya } & \multicolumn{2}{|c|}{$\begin{array}{r}\text { Türkiye } \\
\end{array}$} & \multirow{2}{*}{$\begin{array}{c}\text { Türkiye'nin } \\
\text { Dünyadaki Payı } \\
(\%)\end{array}$} \\
\hline & Miktar (Ton) & Değişim (\%) & Miktar (Ton) & Değişim (\%) & \\
\hline 2005 & 1.804 .165 & 100.00 & 150.000 & 100.00 & 8.31 \\
\hline 2006 & 1.854 .599 & 102.80 & 129.614 & 86.41 & 6.99 \\
\hline 2007 & 1.983 .722 & 109.95 & 172.572 & 115.05 & 8.70 \\
\hline 2008 & 2.242 .179 & 124.28 & 170.897 & 113.93 & 7.62 \\
\hline 2009 & 2.475 .300 & 137.20 & 177.298 & 118.20 & 7.16 \\
\hline 2010 & 2.767 .609 & 153.40 & 178.142 & 118.76 & 6.44 \\
\hline 2011 & 3.198 .938 & 177.31 & 183.240 & 122.16 & 5.73 \\
\hline 2012 & 3.660 .147 & 202.87 & 203.212 & 135.47 & 5.55 \\
\hline 2013 & 3.007 .937 & 166.72 & 212.140 & 141.43 & 7.05 \\
\hline 2014 & 3.385 .873 & 187.67 & 180.807 & 120.54 & 5.34 \\
\hline 2015 & 3.589 .651 & 198.96 & 190.000 & 126.67 & 5.29 \\
\hline 2016 & 3.747 .549 & 207.72 & 195.000 & 130.00 & 5.20 \\
\hline 2017 & - & - & 210.000 & 140.00 & - \\
\hline
\end{tabular}

Kaynak: FAOSTAT verilerinden yararlanarak hazırlanmıştır (Anonim, 2018a).

Çizelge 2. Dünyada Önemli Ceviz Üreticisi Ülkeler

\begin{tabular}{lrr}
\hline Ülke & Üretim Miktarı & Pay (\%) \\
\hline Çin & 1.785 .879 & 47.65 \\
ABD & 607.814 & 16.22 \\
İran & 405.281 & 10.81 \\
Türkiye & 195.000 & 5.20 \\
Meksika & 141.818 & 3.78 \\
Ukrayna & 107.990 & 2.88 \\
Şili & 73.529 & 1.96 \\
Özbekistan & 53.116 & 1.42 \\
Toplam (8 Ülke) & 3.370 .427 & 89.93 \\
\hline Dünya Toplami & 3.747 .549 & 100.00 \\
\hline Kaynak: FAOSTAT 2016 verisinden hesaplanmiştır (Anonim, 2018a). &
\end{tabular}


Türkiye'de ceviz üretimi ülkenin tamamına yakın bir coğrafik alana yayılmıştır. Bununla birlikte üretimin \% 50-60 kadarı 20 ilde gerçekleştirilmektedir. Türkiye'de önemli ceviz üreticisi iller arasında ilk sırada Kahramanmaraş bulunmaktadır. Bu ilimizi Antalya, Denizli, Bursa ve Çorum illeri takip etmektedir (Çizelge 3).

Çizelge 3. Türkiye'de önemli Ceviz Üreticisi İller

\begin{tabular}{lrr}
\hline İller & Miktar (ton) & Pay (\%) \\
\hline Kahramanmaraş & 10.902 & 5.19 \\
Antalya & 8.101 & 3.86 \\
Denizli & 7.962 & 3.79 \\
Bursa & 7.409 & 3.53 \\
Çorum & 6.938 & 3.30 \\
Mersin & 6.452 & 3.07 \\
Sakarya & 6.258 & 2.98 \\
Karaman & 5.763 & 2.74 \\
Van & 5.732 & 2.73 \\
Aydın & 5.350 & 2.55 \\
Kastamonu & 5.112 & 2.43 \\
Balıkesir & 5.085 & 2.42 \\
Tokat & 5.077 & 2.42 \\
Kütahya & 4.935 & 2.35 \\
Amasya & 4.649 & 2.21 \\
Hakkâri & 4.593 & 2.19 \\
Kocaeli & 4.528 & 2.16 \\
Manisa & 4.520 & 2.15 \\
İzmir & 4388 & 2.09 \\
Bitlis & 4.071 & 1.94 \\
Toplam (20 İl) & 117.825 & 56.1 \\
\hline Toplam (Türkiye) & 210.000 & 100.00 \\
\hline Kaynak: TUíK 2017'den yararlanarak hazırlanmıstır (Anonim, 2018b). & &
\end{tabular}

Yeterlilik: Türkiye'nin ceviz üretimi yıllara bağlı olarak düzenli olarak artmaktadır. Bununla birlikte Türkiye'de yaşayan nüfusun 82,0 milyon (Anonim, 2018a) kadar olduğu dikkate alındığında yılda (2017'e göre) kişi başına 2.5-3 kg civarında ceviz üretilmektedir. Ülke nüfusunun ve ceviz tüketimini hızla artması cevizde yeterlilikte azalmaya neden olmuştur. Nitekim cevizde yeterlilik 2000'de \%93,9 iken 2017'de \% 76,7'e gerilemiştir (Çizelge 4). Türkiye'nin ceviz ihtiyacını kendi iç üretimi ile karşılayamaması sonucunda artan iç talep ithalat ile karşılanmaya çalışılmaktadır. Bu durum dikkate alındığında Türkiye'nin ceviz dış ticaretinin ortaya konulması gerekir.

\subsection{Dıș ticaret}

Türkiye'nin ceviz dış ticaretinde hem ihracat hem de ithalat yapan bir ülkedir. Türkiye'nin ceviz dış ticaretine ihracat değerleri dikkate alınarak incelendiğinde 2000-2016 döneminde dalgalı bir durum gösterdiği 2013 yılına kadar arttığı sonrasında ise azaldığı anlaşılmaktadır. İnceldiğimiz dönemde Türkiye'nin ceviz ihracatı 2000'de 968 ton kadarken, 2016'da 8 bin tondur (Çizelge 4). Bu durum dalgalanmalar dikkate alınmaz ise ihracat artışı olumlu değerlendirilebilir. Diğer yandan cevizin toplam ihracat değeri 2012-2016 periyodunda dünyada artarken Türkiye'nin ki azalmıştır (Çizelge 5). Diğer yanda Dünya ceviz ihracatında Türkiye 2012'de \% 2,44 paya sahipken 2016'da \% 0,72'e düşmüştür. $\mathrm{Bu}$ sonuçlar Türkiye'nin ceviz ihracatında bir gerileme olduğunu göstermektedir. Türkiye'nin ceviz üretiminde 4. sirada olmasına rağmen ceviz ihracatında daha gerilerde olduğu bildirilmiştir (Özçağıran ve ark., 2007; Şen, 2011; Yücer, 2013). Bu kaynaklar Türkiye'nin ihracat konusundaki bu durumun standart ceviz çeşitleri ile kurulu bahçe azlığ ve üretilen ceviz meyvelerinin standart eksikliğinden kaynaklarda belirtilmektedir Hiç şüphesiz bu durum ceviz ihracatında Türkiye'nin rekabet gücünü olumsuz etkileyecektir. 
Çizelge 4. Türkiye'nin Ceviz Dış Ticareti ve Yeterlilik Düzeyi.

\begin{tabular}{cccc}
\hline Y1llar & İhracat (Ton) & İthalat1(ton) & Yeterlilik (\%) \\
\hline 2000 & 968 & 8.321 & 93.9 \\
2001 & 767 & 7.949 & 94.0 \\
2002 & 252 & 18.951 & 86.2 \\
2003 & 712 & 25.640 & 83.6 \\
2004 & 916 & 35.972 & 77.8 \\
2005 & 642 & 28.382 & 84.1 \\
2006 & 1.000 & 26.712 & 83.1 \\
2007 & 2.915 & 39.572 & 82.1 \\
2008 & 3.859 & 35.018 & 84.3 \\
2009 & 6.383 & 46.004 & 81.4 \\
2010 & 7.309 & 31.076 & 88.0 \\
2011 & 13.711 & 46.338 & 84.6 \\
2012 & 11.998 & 40.009 & 87.6 \\
2013 & 14.171 & 30.479 & 92.7 \\
2014 & 8.407 & 34.285 & 87.2 \\
2015 & 7.917 & 63.800 & 76.8 \\
2016 & 8.167 & 66.008 & 76.7 \\
\hline
\end{tabular}

Kaynak: FAOSTAT, TUIK ve BEGÜM verilerinden yararlanarak hazırlanmıştır (Anonim, 2018a,b,c).

Bu araştırma kapsamında incelediğimiz Türkiye'nin ceviz ithalatı 2000-2016 periyodunda bir önceki yıla göre artan veya azalan bir seyir izlemiştir. Ancak Türkiye'nin ceviz ithalatı incelenen dönemin başında (2000'de) 8 bin ton kadarken sonunda (2016'da) 66 bin tona yükselmiștir (Çizelge 4). $\mathrm{Bu}$ değişim iç pazar taleplerinin karşılanmasında ithalatın öneminin arttı̆̆ını göstermektedir. Nitekim Dünya'da en fazla ceviz ithal eden ülkeler arasında Türkiye'nin de olduğu bildirilmiştir (Şen, 2011; Yücer, 2013).

$\mathrm{Bu}$ verilere göre Türkiye ceviz dış ticareti konusunda ithalat miktarı ihracat miktarından daha yüksek bir ülkedir. Bu durum Türkiye'nin rekabet gücünü etkileyecektir.

\subsection{Rekabet gücü}

Türkiye ceviz dış ticaretinde açık veren bir ülke konumundadır. Türkiye'nin rekabet gücü bu çalışma kapsamında 2012-2018 döneminde incelenmiştir. Öncelikle Ülkemizin ceviz ihracatı değer olarak 2012 yılında60,0 milyon dolar iken 2016 yılında 21,4 milyon dolara gerilemiştir (Çizelge 5). $\mathrm{Bu}$ durum ekonomik gelişmeler ile ilişkilidir. Benzer şekilde 2012-2016 döneminde Karşılaştırmalı Üstünlük Katsayısı azalma eğilimindedir. Bu eğilim 2012-2015 döneminde 2'den daha büyük olarak belirlenmekle, 2016'da 0,8'e düşmüştür (Çizelge 5). AKÜ katsayısı değeri 1'den büyükse o ülkenin ilgili üründe (mal veya sektör) karşılaştırmalı üstünlüğe sahip olduğu kabul edilir. Bunun yanında eğer AKÜ katsayısı değeri 1'den küçük ise ilgili üründe o ülkenin karşılaştırmalı üstünlüğü olmadığ1 anlamına gelir (Bashimov, 2016). Bu katsayının 2 ile 4 arasında olması bir ülkenin orta derecede ihracatında karşılaştırmalı üstünlüğe (rekabet gücüne)sahip olduğunu göstermektedir (Hinloopen ve Marrewijk, 2001). Bu çalışmada elde edilen bulgular Türkiye'nin rekabet gücünün 2012-2015 döneminde orta dereceden olduğunu ancak 2016 yılında bir avantajının kalmadığını göstermektedir.

Tablo 5. Cevizde Toplam İhracat değeri ve rekabet katsayısı

\begin{tabular}{lccccc}
\hline Y1l & $\begin{array}{c}\text { Dünya } \\
(1000 \text { dolar })\end{array}$ & $\begin{array}{c}\text { Türkiye } \\
(1000 \text { dolar })\end{array}$ & $\begin{array}{c}\text { Türkiye'nin Pay1 } \\
(\%)\end{array}$ & Rekabet katsay1s1 & $\begin{array}{c}\text { Üstünlük } \\
\text { Derecesi }\end{array}$ \\
\hline 2012 & 2.461 .072 & 60.100 & 2.44 & 2.868858 & Orta \\
2013 & 2.768 .356 & 46.791 & 1.69 & 2.03768 & Orta \\
2014 & 3.153 .732 & 64.128 & 2.03 & 2.377351 & Orta \\
2015 & 3.182 .669 & 58.504 & 1.84 & 2.106975 & Orta \\
2016 & 2.955 .054 & 21.377 & 0.72 & 0.809791 & Dezavantaj \\
\hline
\end{tabular}

Kaynak: FAOSTAT verilerinden (Anonim, 2018a) yararlanarak hazırlanmıştır. 
$\mathrm{Bu}$ incelemeden elde edilen bulgulara göre Türkiye'nin ceviz ihracatında rekabet gücüne sahip olduğu ve incelenen dönemde yıllara göre farklılıklar olmakla birlikte Türkiye'nin ceviz ihracatındaki rekabet gücünün son birkaç yılda azaldığı belirlenmiştir.

\section{Sonuç}

Türkiye önemli bir sert kabuklu kuru meyve olan ceviz üretimini artırmaya çalışmasına rağmen henüz kendine yeterli duruma gelmemiştir. Artan nüfus ve cevize olan talebin her geçen gün artması beraber kendine yeterliliğin 2000-2016 döneminde daha da azalması ile sonuçlanmıştır. Ülke içi ihtiyaç üretimle tamamen karşılanamadığında ithalat miktarı da incelenen dönemde artmıştır. Türkiye ceviz dış ticaretinde açık veren bir ülke durumundadır.

Dünyada ihracatı yapılan ürünler faktör yoğunluğuna göre beş ana gruba ayrılmaktadır. Bunlar; hammadde, emek ve sermaye yoğun olanlar yanında Ar-Ge temelli kolay ve zor taklit edilen ürünlerdir (Erkan ve ark., 2015). Bu ayrımda zirai ürünleri hammadde yoğun ürün grubu içerisinde değerlendirilmektedir. İhracatta rekabet gücü bakımından Türkiye'nin emek ve sermaye yoğun malların ihracatında olduğu bildirilmiştir (Erkan, 2012b). Bahçe ürünlerinin üretimlerinde diğer zirai ürünlere göre daha fazla emeğe gereksinim duyulmaktadır. Bu sebeple bu grup ürünlerde ihracat potansiyeli ve imkânı yüksek olan ürünlerin üretimi ağırlık vermek gerekir. Bu durum dikkate alınarak ceviz üretiminde yerel ve uluslararası pazarların standartlarını karşılamak için modern tekniklere yer verilmeli; katma değeri yaratmak için cevizden elde edilen mamul ürünler artırılmalıdır. $\mathrm{Bu}$ çalışmadan elde edilen cevizin rekabet gücü ile ilgili bulgular bu konuda önceki bir çalışma sonuçları (Ketenci ve Bayramoğlu, 2018) ile paralellik arz etmektedir. Bu incelemeden elde edilen bulguların ışığında cevizde yeterlilik düzeyinin ve standart meyve özelliklerine sahip ceviz üretiminin artırılmasına ihtiyaç vardır. Kaldı ki, Türkiye sahip olduğu potansiyel dikkate alındığında Türkiye'nin ceviz üretiminde alacağı tedbirlerle üretim, dış satım ve rekabet gücünü artırması mümkündür.

\section{Kaynakça}

Anonim, (2018a). Food and Agriculture Organization of the United Nations (FAO). FAOSTAT, http://www.fao.org/faostat/en/\#data/QC. Erişim Tarihi: 11.05.2018.

Anonim, (2018b). Bitkisel Üretim İstatistikleri. Tarım ve Ormancılık Bakanlığı Bitkisel Üretim Genel Müdürlüğ̈̈ (BUGEM), https://www.tarim.gov.tr/BUGEM/Menu/9/Veriler. ErişimTarihi: 03.04.2018.

Anonim, (2018c).Bitkisel Üretim İstatistikleri.TUIK, $\underline{\text { http://www.tuik.gov.tr/ }}$ PreTablo.do?alt id=1001. Erişim Tarihi: 01.05.2018.

Bashimov, G. (2016). Türkiye'nin Domates İhracat Performans1 ve Rekabet Gücü. (bk. http://dergipark.gov.tr/download/article-file/311449).

Beningo, S. (2006). Trade and Transportation Between the United States and China and Between the United States and India. Conference of the Society of Government Economists, 27 October 2005, Washington, p: 6.

Bojnec, S., \& Fertő, I. (2006). Does comparative advantages in agro-food trade matter for multifunctional rural development: the case of Hungary and Slovenia. Journal of Central European Agriculture, 7(3), 583-586.

Coxhead, I. (2007). A new resource curse? impacts of China's boom on comparative advantage and resource dependence in Southeast Asia. World Development, 35 (7), 1099-1119.

Erkan, B. (2012a). BRIC Ülkeleri ve Türkiye'nin ihracat uzmanlaşma ve rekabet düzeylerinin karşılaştırmalı analizi. Ekonomik ve Sosyal Araştırmalar Dergisi, 8 (1),101-131.

Erkan, B. (2012b). Türkiye'nin geleneksel ihraç tarım ürünlerinde uzmanlaşma düzeyi. Sosyal ve Beşeri Bilimler Dergisi, 4(1),75-83.

Erkan, B., Arpacı, B. B., Yaralı, F., \& Güvenç, İ. (2015). Türkiye'nin sebze ihracatında karşıllaştırmalı üstünlükleri. KSÜ Doğa Bil. Dergisi, 18(4), 70-76.

Fertö, I., \& Hubbard, L. J. (2001). Regional Comparative Advantage and Competitiveness in Hungarian Agri Food Sectors. $77^{\text {th }}$ EAAE Seminar / NJF Seminar No. 325, August 17-.

Hinloopen, J., \& Marrewijk, C.V. (2001). On the empirical distribution of the Balassa Index. Review of World Economics, Vol: 137, No:1, March 2001, P: 13. 
Ketenci C. K., \& Bayramoğlu, Z. (2018). Türkiye'de ceviz üretiminin rekabet analiz. Türk Tarım ve Doğa Bilimleri Dergisi 5(3), 339-347.

Mykhnenko, V. (2005). What Type of Capitalism in Eastern Europe? Institutional Structures, Revealed Comparative Advantages and Performance of Poland and Ukraine. Centre for Public Policy for Regions (CPPR) Discussion Paper, No:6, September 2005, p:27.

Özçağıran, R., Ünal, A., Özeker, E., \& İsfendiyeroğlu, M. (2007). Ilıman İklim Meyve Türleri: Sert Kabuklu Meyveler, Cilt III, EÜ Ziraat Fakültesi Yayınları No: 566, S: 308.

Şen, S. M. (2011). Ceviz. ÜÇM yayıncılık Ankara, S: 220.

Y1lmaz, B., \& Ergun, S.J. (2003). The Foreign Trade Pattern and Foreign Trade Specialization of Candidates of The European Union. Ezoneplus Working Paper, Fifth Framework ProgrammeEuropean Commission, No: 19, Sep. 2003, P: 8.

Yinanç, R., \& Elibüyük, M. (1988). Maraş Tahrir Defteri. Osmanlı Tarihi Araştırma ve Uygulama Merkezi Yayınları No: 1, S: 468.

Yücer, M.M. (2013). Ceviz. Hasad yayıncılık, İstanbul, S: 92. 